\title{
TENGO 50 AÑOS ¿Y QUÉ?. DIFICULTADES Y ESTRATEGIAS EN EL RETORNO AL MERCADO DE TRABAJO
}

\author{
Fco. Javier Rubio Arribas. \\ Sociólogo y especialista en Sociología del Consumo ${ }^{1}$, Madrid.
}

http://dx.doi.org/10.5209/rev_NOMA.2013.v40.n4.48338

\begin{abstract}
Resumen.- No es igual que se encuentre desempleada una persona de 23 años que una con 50 o más, por lo que oportunidades, necesidades y circunstancias... son diferentes, y la actitud de base/inicio también es distinta en ambos casos. El tema de la edad se vuelve un hándicap cuando en realidad debería ser tenido en cuenta como un valor añadido (la experiencia es un grado, siempre nos lo han dicho). Y por otro lado, si el proceso de búsqueda de un empleo, se alarga mucho en el tiempo, se vuelve tremendamente complicado el retorno, pues la frustración hace mella y todo se vuelve más cuesta arriba. A la propia pérdida de motivación relacionada directamente con el tiempo en desempleo se añaden una serie de factores que pueden generar más dificultades, como por ejemplo la edad. Lo que está claro es que la edad no se puede cambiar, no se puede hacer nada por reducirla, es la que es y punto. Aunque las dificultades puedan ser más que las ventajas, debemos ser capaces de sacarle el máximo partido posible, centrándonos en lo que podemos ofrecer y tratar de minimizar el factor de la edad como un factor determinante. El trabajo adquiere un significado relevante para las personas mayores de 45 y más si cabe para las que tienen más de 50, de forma que el acceso al empleo se percibe como un recurso para lograr satisfacer diferentes necesidades: básicas, personales, familiares, etc.
\end{abstract}

Palabras clave.- Parados y paradas de larga duración; la edad como frontera negativa; tener más de 50 años: doble castigo; reinserción laboral; estrategias en su inserción laboral; sensaciones de exclusión y aislamiento; inestabilidad laboral; dinámicas de exclusión; políticas activas de empleo.

Summary.- Is not the same as unemployed, a person of 23 years or with 50 or more. Theirs opportunities, needs, and circumstances ... are different. The basic attitude/start is also different in both cases. The topic of the age becomes a "handicap", when in fact, it should be taken into account, as a "value-added". "The experience is a degree" is a Common phrase. On the other hand, if the process for finding a job, it takes a long time, it becomes extremely complicated return, because the frustration "leave track". To the own loss of motivation, directly related to the time in unemployment, adds a number of factors that can create more difficulties, such as age. Let me be clear, the age cannot be changed. Nothing can be done to reduce. Our Age, is only our "biological" fact. Although the difficulties may be more than the benefits, we must be able to focused, on what we can offer as worker, and try to minimize the factor of age. The work acquires a meaning relevant to people older than 45, 50 age. As conclusion the access to employment must be a resource to meet different needs: basic, personal, family, etc.

Key Words.- Unemployed and long-term unemployed; the age as negative factor; The Older age as a double punishment; re-employment; strategies in their insertion in the labor market;

\footnotetext{
${ }^{1}$ He trabajado en el campo de la inserción laboral de personas con discapacidades, así como en la realización de investigaciones empíricas sobre esta temática. Llevo varios años compartiendo la investigación social y de mercados (como sociólogo-consultor) con la orientación e intermediación laboral (en asesoría laboral). Pertenezco al colectivo de personas de más de 50 años.
} 
feelings of exclusion and isolation; job instability; exclusion relationships; active employment policies.

\section{Introducción}

Para la población asalariada el ajuste de la crisis se puede calificar de brutal, en términos de destrucción de empleo y empeoramiento de las condiciones de vida, en especial para los aproximadamente ocho millones de personas activas que alternan períodos de paro y empleo temporal, sobre todo cuando no perciben prestaciones ni subsidios (aproximadaente el 30\%) o donde todos los miembros activos de la unidad doméstica se encuentran en situación de desempleo (más de 1 millón de hogares).

Estamos asistiendo a una sociedad fracturada y/o brecha social entre aquellas personas que tienen un empleo/trabajo y por ende, recursos económicos y aquellos que no tienen un empleo, y por tanto, depende su fuente de ingresos económicos de prestaciones, subsidios, ayudas (Renta Activa de Inserción y/o Renta Mímia de Inserción...) de las administraciones públicas. Incrementándose la desigualdad social entre unos y otros, que ha venido acompañada por una disminución progresiva de los recursos de protección social pública, en su vertiente más reedistributiva y asistencial ${ }^{2}$.

Por otro lado, no debemos olvidar que de los casi 6 millones de personas desempleadas -el 33\% aproximadamente- tienen más de 40 años, lo que equivale a 2 millones de personas; o lo que es lo mismo, 1 de cada 3 personas en búsqueda de empleo, es mayor de $\mathbf{4 0}$ años. Según datos de la

\footnotetext{
${ }^{2} \mathrm{Al}$ reducirse los ingresos de muchos hogares, se han disparado los desahucios y los embargos, y se han saturado los servicios de atención a personas sin hogar. Como resultado, España es cada vez más desigual, tanto en términos de reparto de la renta que se produce cada año como, sobre todo, en términos de distribución de la riqueza acumulada a lo largo del tiempo. En España ya hay tres millones de personas en situación de "pobreza severa" (según la terminología de Cáritas), esto es que viven con menos de 307 euros al mes. Los pobres representan el $\mathbf{6 , 4 \%}$ de la población del país, una tasa que casi duplica la de 2007 $(3,5 \%)$, según datos de la Encuesta de Condiciones de Vida recogidos en el informe del Observatorio de la Realidad Social 2012 elaborado por Cáritas. La organización católica alerta de la irrupción de "una segunda oleada de empobrecimiento y exclusión social" agudizada por "las políticas de ajustes y sus recortes, la prolongación de las situaciones de desempleo, el agotamiento de las ayudas económicas".
} 
última Encuesta de Población Activa (EPA) $3^{\circ}$ Trimestre de $2013^{3}$, el número de parados mayores de 55 años representa el $\mathbf{9 , 7 \%}$ de las 5.904 .700 personas desempleadas ${ }^{4}$ y tienen menos márgen de maniobra ${ }^{5}$. Entre 2007 y 2013 el número de parados mayores de $\mathbf{5 0}$ años se ha cuadruplicado. $Y$ no debemos olvidar que han perdido su empleo involuntariamente ${ }^{6}$ (y que cuanto más

\footnotetext{
${ }^{3}$ Según los datos del $3^{\circ}$ Trimestre de 2013 de la EPA (INE, Madrid), el total de personas desempleadas se eleva a 5.904.700. Y la tasa de paro según los grupos de edad en ambos sexos es:
}

- Entre 16 y 19 años, el 4,0\%.

- Entre 20 y 24 años, el $12,0 \%$.

- Entre 25 y 54 años, el $\mathbf{7 4 , 3 \%}$.

- De 55 años y más, el 9,7\%.

Hombres: 3.138 .700

- Entre 16 y 19 años, el 4,0\%.

- Entre 20 y 24 años, el 12,0\%.

- Entre 25 y 54 años, el 73,2\%.

- De 55 años y más, el 10,8\%

Mujeres: 2.766 .000

- Entre 16 y 19 años, el 3,9\%.

- Entre 20 y 24 años, el $12,1 \%$.

- Entre 25 y 54 años, el $75,4 \%$.

- De 55 años y más, el 8,6\%.

La tasa de paro de la zona euro se situó el mes de octubre en el 12,1\%, una décima menos que en septiembre, pero cuatro por encima del dato del año anterior, según ha informado la oficina comunitaria de estadística, Eurostat, que vuelve a situar a Grecia y a España a la cabeza de la destrucción de empleo, con tasas de paro del $27,3 \%$ y el $26,7 \%$, respectivamente. En el conjunto de la Unión Europea, la tasa de desempleo se mantuvo sin cambios respecto a agosto en el 10,9\%, un El paro registrado logró bajar en noviembre de 2013 pese a que siempre había subido durante este mes desde, al menos, 1997. El recorte, sin embargo, ha sido mínimo, de apenas 2.475 personas con respecto a octubre, con lo que el total de desempleados apuntados al antiguo Inem se queda sobre los 4,8 millones. Del lado del empleo, la afiliación, que había logrado mejorar en octubre de la mano de los contratos temporales, vuelve a retroceder y se queda en 16.293 .543 ocupados. El retroceso, en cualquier caso y en línea con esta tendencia de los meses previos, es inferior al sufrido en 2012 y en 2011, cuando cayó en unas 205.700 y 111.800 personas, respectivamente. Con respecto a noviembre de 2012, la afiliación vuelve a bajar y retrocede en 237.505 ocupados, lo que supone una caída del 1,44\%. Por tanto, el empleo creado es altamente temporal.

El número de personas paradas registradas en los Servicios Públicos de Empleo en el mes de noviembre, en la Comunidad de Madrid bajó en 2.489 personas, un 0,45\%, lo que sitúa la cifra de desempleados en 550.269 personas registradas. Según los datos del Ministerio de Empleo y Seguridad Social, en los últimos 12 meses el paro registrado en Madrid ha descendido en 3.493 personas, un 0,63\%. En comparación con el mes de noviembre de 2012, el paro en la región ha bajado en 3.493 personas, lo que supone un descenso anual del 0,63\%.

${ }^{4}$ No debemos olvidar que el colectivo de personas mayores de $\mathbf{5 0}$ años, son designados como de muy difícil inserción laboral (o deberíamos decir reinserción, ya que seguramente habrán perdido uno más empleos). También se habla del doble "castigo" de las personas de mayor edad, por una lado, las ofertas de empleo hacia esta colectivo, disminuyen drástica y dramáticamente y por el otro, se recortan los subsidios.

${ }^{5}$ Entendiendo por margen de maniobra la posibilidad de reciclarse, de formarse, de hacer las maletas y emigrar, y la disposición de redes familiares que amortiguan la situación en el caso de los jóvenes. Los más mayores, en cambio, son los que forman la propia red familiar.

6 Quedarse sin trabajo es una situación actualmente muy estresante y muy dura, especialmente para colectivos específicos con mayor dificultad de inserción laboral. Este es el caso de los mayores de 50 años. Las personas desempleadas identifican claramente dos aspectos que parecen ser importantes barreras para lograr su reincorporación al mercado de trabajo. En primer lugar, se aprecia una percepción estereotipada en base a la cual la edad parece influir en la propia capacidad de la persona para realizar diferentes actividades ligadas 
tiempo permanezcan desempleados más puede bajar su autoestima). La pérdida de empleo resulta siempre traumática para los trabajadores afectados y para la Sociedad en su conjunto.

Uno de los principales problemas con los que las personas mayores de 45 años se encuentran a la hora de buscar trabajo, es precisamente, el largo tiempo que Ilevan sin hacerlo ${ }^{7}$ y la dificultad de insertabilidad ${ }^{8}$ como una de las señas de identidad del colectivo. Deben volver a elaborar un curriculum, debiendo saber dónde buscar empleo o cómo enfrentarse a una entrevista de trabajo, éstos son algunos sencillos pasos que pueden ser un freno para el desempleado de estas edades. Otro puede ser su mayor desmotivación, atribuyendo su situación de desempleo a la edad excesiva y a una falta de orientación laboral adecuada para este colectivo. Que se verbaliza con frases como "no les interesa cogerme por mi edad"; "no me van a llamar porque soy mayor" o "más ayudas a las personas mayores de 50 años, que no conseguimos encontrar empleo por nuestra edad". Este recurso de culpabilizar a su edad (como factor de desventaja social) lleva a este colectivo a adoptar una actitud pasiva a la hora de buscar un empleo o a la hora de recibir formación.

Lo más preocupante es el «coste humano» de las personas y familias que se ven abocadas y/o expulsadas del mercado de trabajo. Y que genera quiebra en los proyectos personales, familiares y grupales, además, de excesivos vaivenes en los proyectos de vida de las personas.

Por último, el gobierno actual del Partido Popular ha introducido modificaciones legislativas $^{9}$ en las relaciones del mercado de trabajo y

al ámbito laboral y, en segundo lugar, no estar dentro de la filosofía empresarial de contratación. En otras palabras, las personas que tienen más de 50 años, consideran que tienen más dificultades para ser contratadas debido a su edad. Esta percepción de la edad como un factor de desventaja -imagen social inadecuada y poco apropiada del colectivo- se encuentra intensamente interiorizada por las personas.

${ }^{7}$ El problema del desempleo se incrementa aún más, cuando adquiere el carácter de "larga duración", y en los últimos años se complica mucho más volver al mercado laboral si le añadimos el hándicap de tener una edad superior a los 45 años.

${ }^{8}$ Hay que tener en cuenta, que las personas desempleadas mayores de 45 años han tenido una trayectoria profesional más "estable" en cuanto a puestos de trabajo y, por tanto, a tareas a desarrollar. Por lo que se les considera que tienen una menor versatilidad en el puesto de trabajo. Debemos de entender por versatilidad, la capacidad de realizar diversas tareas dentro de un mismo puesto de trabajo. De ahí que sea necesario desarrollar en mayor medida esa versatilidad en el puesto de trabajo, ya que los responsables de RR. $\mathrm{HH}$. de las empresas lo señalan como un punto débil de este colectivo a mejorar.

${ }_{9}$ Ante la supuesta debilidad del mercado laboral español y ante la crisis económica que estamos atravesando desde 2008, este gobierno del PP -gracias a su amplia mayoría 
recortes en los subsidios ${ }^{10}$. Desde que se inició el proceso de Reforma Laboral en España durante el año 2012, se han producido importantes cambios normativos que afectan a la Políticas de Empleo, y muy especialmente a los Programas de incentivos previstos para la contratación en sus distintas modalidades.

En los últimos años se han sucedido los llamados "Programas de Fomento de Empleo" donde era habitual encontrar algunos colectivos con especiales dificultades para acceder al mercado de trabajo, como eran las personas con discapacidades, los jovenes, las personas mayores de 45, las mujeres y las personas desempleadas de larga duración, entre otros.

El entorno de crisis económica en el que nos encontramos desde 2009 y la acuciante necesidad del Estado de reducir costes laborales, que se han agudizado a medida que ha avanzado la destrucción de empleo y, consecuentemente, el gasto en desempleo, ha llevado a un replanteamiento en la Política de Empleo que se venía aplicando hasta el momento.

absoluta- introduce o nos impone la Reforma Laboral -Real Decreto-ley 3/2012, de 10 de febrero, de medidas urgentes para la reforma del mercado laboral; BOE $n^{\circ} 36$, sábado 11 de febrero de 2012 y que según este Real Decreto-ley entro en vigor al día siguiente de su publicación en el Boletín Oficial del Estado. En el mes de Julio, nos impusieron el Real Decretoley 20/2012, de 13 de julio, de medidas para garantizar la estabilidad presupuestaria y de formento de la competitividad-BOE no 168 sábado 14 de Julio de 2012- donde se suprimieron las bonificaciones que tenían los empresarios por contratar a mayores de 45 años, y actualmente según Ley 4/2013 estas se limitan a la contratación en nuevos proyectos empresariales de emprendimiento joven, y para empresas de menos de 50 trabajadores que contraten a mayores de 45 años desempleados inscritos en la oficina de empleo. Ambas hasta que la tasa de desempleo se sitúe por debajo del 15\%. De este tipo de contratos según las estadísticas del SEPE, se han realizado muy pocos. Por último, y curiosamente en el Real Decreto-ley 5/2013, de 15 de marzo, de medidas para favorecer la continuidad de la vida laboral de los trabajadores de mayor edad y promover el envejecimiento activo -BOE núm. 65, de 16 de marzo de 2013; corrección de errores y erratas BOE núm. 81, de 4 de abril de 2013-, de medidas para favorecer la continuidad de la vida laboral... "Se establece que los trabajadores mayores de 55 años que hayan agotado la prestación por desempleo o que no tengan derecho a la misma, tendrán la consideración de colectivo protegido prioritario para la aplicación de políticas activas de empleo a fin de fomentar su permanencia en el mercado de trabajo y prolongar su vida laboral". Hasta el momento el gobierno no ha desarrollado medida alguna al respecto. La Reforma Laboral ha facilitado el despido y sobre todo el de contratados indefinidos. Quien pierde un trabajo difícilmente vuelve a encontrar otro, escenario que se complica mucho con la edad.

${ }^{10}$ Desde julio del 2012, el subsidio por desempleo -426 euros mensuales- ha sufrido varios recortes; por un lado, se ha eliminado el subsidio extraordinario que había para mayores 45 años; se ha aumentado el límite de edad para el ordinario de 52 años a 55; se ha introducido un nuevo requisito al contar los ingresos de toda la unidad familiar y no solo del parado para acceder a él; se obliga a acceder a la jubilación a la primera edad posible eliminando la posibilidad de esperar hasta cumplir los 65 años y tres meses. En fin, este gobierno está introduciendo reducciones económicas en los subsidios. 
A continuación se muestra un cuadro con las bonificaciones más importantes y que afecta principalmente a las personas mayores de 45 años.

\section{BONIFICACIONES/REDUCCIONES A LA CONTRATACIÓN}

Bonificaciones/Reducciones a la contratación laboral. Cuadro resumen de normativa vigente.

\begin{tabular}{|c|c|c|c|c|c|c|}
\hline $\begin{array}{l}\text { Tipo de } \\
\text { Contrato }\end{array}$ & \multicolumn{2}{|c|}{ Colectivo } & Cuantía & Duración & $\begin{array}{l}\text { Vigencia } \\
\text { de la } \\
\text { Medida }\end{array}$ & Normativa \\
\hline $\begin{array}{l}\text { Contratación } \\
\text { en nuevos } \\
\text { proyectos de } \\
\text { emprendimiento } \\
\text { joven. } \\
\text { INDEFINIDO }\end{array}$ & \multicolumn{2}{|c|}{ Mayor de 45 años (1) } & $\begin{array}{l}\text { Reducción } \\
\text { del } 100 \% \text { de } \\
\text { la cuota } \\
\text { empresarial a } \\
\text { la Seguridad } \\
\text { Social. }\end{array}$ & 12 meses & $\begin{array}{l}\text { Hasta que } \\
\text { la tasa de } \\
\text { desempleo } \\
\text { se sitúe } \\
\text { por debajo } \\
\text { del } 15 \% \text {. }\end{array}$ & $\begin{array}{l}\text { Ley } \\
4 / 2013 . \\
\text { ( Art 11) }\end{array}$ \\
\hline \multirow[b]{2}{*}{$\begin{array}{c}\text { Para empresas } \\
\text { de } \\
\text { menos de } 50 \\
\text { trabajadores }\end{array}$} & \multirow{2}{*}{$\begin{array}{l}\text { Mayores de } \\
45 \text { años } \\
\text { desempleados } \\
\text { inscritos en la } \\
\text { oficina de } \\
\text { empleo }\end{array}$} & Desempleados/as & 1.300 & \multirow{2}{*}{3 años } & \multirow[b]{2}{*}{$\begin{array}{l}\text { Hasta que } \\
\text { la tasa } \\
\text { de } \\
\text { desempleo } \\
\text { se } \\
\text { sitúe por } \\
\text { debajo } \\
\text { del } 15 \% \\
\end{array}$} & \multirow{2}{*}{$\begin{array}{c}\text { Ley } \\
3 / 2012\end{array}$} \\
\hline & & $\begin{array}{c}\text { Mujeres } \\
\text { subrepresentadas } \\
\text { (2) }\end{array}$ & 1.500 & & & \\
\hline Indefinido & \multicolumn{2}{|c|}{$\begin{array}{c}\text { Trabajadores desempleados } \\
\text { mayores de } 52 \text { años beneficiarios } \\
\text { de } \\
\text { los subsidios del art. } 215 \text { LGSS, a } \\
\text { tiempo completo y de forma } \\
\text { indefinida (3) }\end{array}$} & $\begin{array}{l}\text { Bonificación } \\
\text { que } \\
\text { corresponda } \\
\text { según el } \\
\text { vigente PFE } \\
\text { (4) }\end{array}$ & $\begin{array}{c}\text { Según la } \\
\text { normativa } \\
\text { aplicable del } \\
\text { PFE }\end{array}$ & $\begin{array}{l}\text { Según la } \\
\text { norma } \\
\text { aplicable } \\
\text { del PFE }\end{array}$ & $\begin{array}{c}\text { - LGSS } \\
\text { (art. 228.4) } \\
y \\
\text { Ley } \\
45 / 2002 \\
\text { (DT 5) } \\
\text { - Ley } \\
43 / 2006\end{array}$ \\
\hline $\begin{array}{l}\text { Mantenimiento } \\
\text {-empleo } \\
\text { trabajadores } \\
\text { mayores }\end{array}$ & \multicolumn{2}{|c|}{$\begin{array}{l}\text { Mayor de } 65 \text { años con } 38 \text { años y } \\
6 \text { meses de cotización } \\
\text { efectiva a la Seguridad Social y } \\
\text { contrato indefinido } \\
\text { (nuevo o vigente) o tener } 67 \text { años } \\
\text { y } 37 \text { de cotización }\end{array}$} & $\begin{array}{c}\text { Reducción } \\
100 \% \text { cuota } \\
\text { empresarial } \\
\text { por } \\
\text { contingencias } \\
\text { comunes, } \\
\text { salvo la } \\
\text { incapacidad } \\
\text { temporal }\end{array}$ & $\begin{array}{c}\text { - Duración } \\
\text { de la } \\
\text { exención: } \\
\text { Indefinida. } \\
\text { - Si el } \\
\text { trabajador no } \\
\text { tiene la } \\
\text { antigüedad } \\
\text { necesaria al } \\
\text { cumplir la } \\
\text { edad, la } \\
\text { exención }\end{array}$ & & $\begin{array}{l}\text { - Ley } \\
\text { General } \\
\text { de la S. } \\
\text { Social } \\
1 / 1994 \\
\text { (art. 112 } \\
\text { bis) } \\
\text { - Ley }\end{array}$ \\
\hline
\end{tabular}




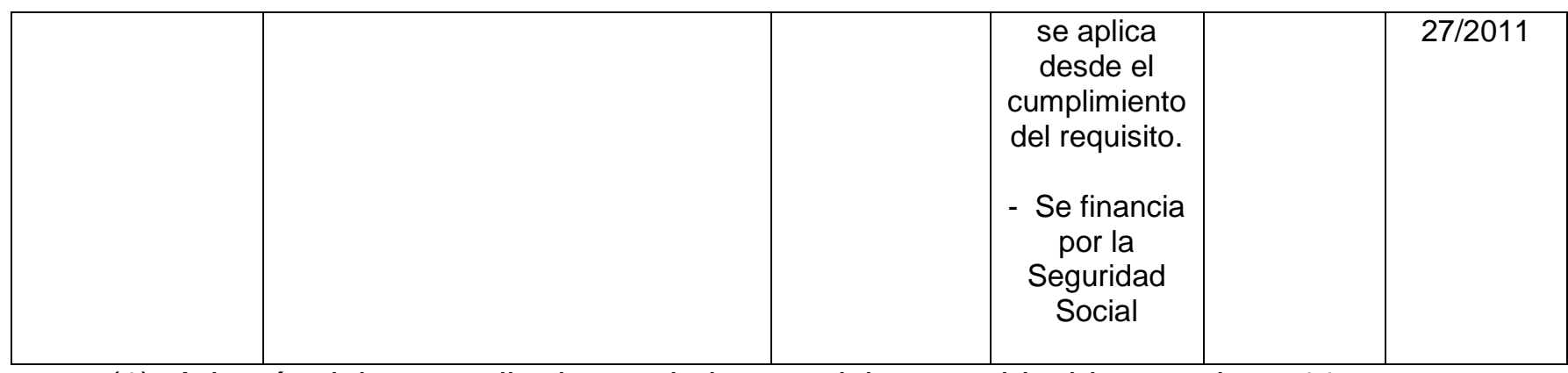

(1) Además debe cumplir alguno de los requisitos establecidos en el art. 11. de la Ley $11 / 2013$.

(2) Mujeres en ocupaciones en los que este colectivo esté menos representado.

(3) Estos trabajadores, que se acogen voluntariamente a este programa, pueden compatibilizar los subsidios por desempleo con el trabajo por cuenta ajena en aplicación de lo previsto en el párrafo primero del apartado 4 del artículo 228 del Texto Refundido de la Ley General de la Seguridad Social.

(4) PFE = Programa de Fomento de Empleo (dependiendo del colectivo, Ley 43/2006 o Ley $3 / 2012$ ).

Fuente: Elboración propia, información extraida del Servicio Público de Empleo Estatal. Madrid, datos actualizados a octubre de 2013.

La gravedad de la crisis actual no tiene precedentes. En España se ha destruido más empleo, y más rápidamente, que en las principales economías europeas $^{11}$. El desempleo de larga duración en España es también más elevado que en otros países de nuestro entorno y cuenta con un doble impacto negativo. Por un lado, el evidente sobre el colectivo de personas y, por otro, el impacto adicional sobre la productividad agregada de la economía. La duración media del desempleo en España en 2010 fue, según la OCDE, de 14,8 meses, frente a una media para los países de la OCDE de 9,6 y de 7,4 meses para los integrantes del G7.

\section{Entorno laboral y social ante el empleo}

La profunda crisis económica que España está padeciendo desde hace ya algunos años (2008/13) ha evidenciado un conjunto de graves problemas sociales derivados de la difícil situación y cambios profundos que está padeciendo el mercado de trabajo ${ }^{12}$. Entre ellos destacan, las dificultades que

\footnotetext{
${ }^{11}$ El paro o desempleo no es otra cosa que la manifestación brutal, el desvelamiento súbito de esta situación estructural, la crisis económica. No es sólo el paro obrero (aunque sea éste el más doloroso, por su mayor indefensión) si no el de los jóvenes, el de las personas extranjeras, el de las mujeres, y el de las personas mayores de 45 años.

12 Así, nos podemos encontrar, a personas o grupos que manifiestan una importante inestabilidad laboral, como resultado de los cambios en el mercado de trabajo o en la economía del país. Aquí podemos encontrarnos con jóvenes con formación profesional o
} 
tienen las personas paradas (especialmente aquellas que tienen cargas familiares y están hipotecadas); las personas inmigrantes (que han sido especialmente castigados por la intensa y profunda destrucción de empleo en sectores como la construcción, los servicios y la hostelería) y la ya perenne precariedad laboral entre los jóvenes ${ }^{13}$.

En muchos casos, el itinerario vital-laboral, vuelve a empezar (entrada-salidaentrada). Por esta razón, el proceso de inserción sociolaboral de las personas desempleadas es cíclico ${ }^{14}$ y recurrente. Estos procesos de entrada y salida rápidos, son quizás mucho más duros para aquellas mujeres y hombres de más de 45 años, y los parados y paradas de larga duración, ya que tienen mucho más que reconstruir. Esta etapa supone el inicio de una ruptura del yotrabajador/a creado/formado dentro del ámbito laboral y que se quiebra/rompe, por lo que las personas que lo sufren, experimentan un profundo vacío en el recorrido de entrada al mercado del trabajo, hasta conseguir un empleo, aunque éste fuera precario ${ }^{15}$. Porque no debemos olvidar, que el empleo, tiene un carácter de identidad social: «se es personas social en el momento en el

estudios universitarios, que son considerados de difícil inserción. También tienen cabida en este grupo de personas, aquellos y aquellas que han adquirido una profesión a través de la experiencia (vendedores y vendedoras; comerciales; electricistas; fontaneros; albañiles; pintores, etcétera), pero que las fluctuaciones del mercado de trabajo (como pueden ser cierre de empresas, EREs, actividades laborales que tienden a desaparecer, etcétera), les llevan a vivir situaciones de desempleo prolongadas (que en muchos casos superan los dos años de desempleo continuado). Dificultando su vuelta o regreso al mercado de trabajo.

${ }^{13}$ En términos generales la precariedad laboral de los jóvenes, ha sido tradicionalmente conceptualizada en términos de temporalidad. De esta manera, aquellos empleos que no aseguraban una estabilidad en el empleo se identificaban automáticamente a la categoría de empleos precarios. La naturalización de la precariedad (es decir, la percepción de la precariedad como elemento constitutivo de la naturaleza de la vida sociolaboral) tiene un claro correlato en la forma en la que se produce el abandono del sistema educativo por parte de los jóvenes. El paro entre los jóvenes españoles duplica la media de la Unión Europea (UE) y supera en más de diez puntos a Eslovaquia, el penúltimo país en peor situación de paro juvenil. ${ }^{14}$ El término "ciclo" según el Diccionario de la Lengua Española, es su primera acepción, se refiere a: "periodo de tiempo o cierto número de años que, acabados, se vuelven a contar de nuevo" y en segunda acepción: "serie de fases por las que pasa un fenómeno periódico hasta que se reproduce una fase anterior".

${ }^{15} \mathrm{La}$ mayoría de las personas que tengan entre 30 y 48 años, han pasado por diversos empleos, prácticamente la mayoría de ellos, temporales y cuando no lo han sido, se ha tratado de empleos de baja cualificación que les ha llevado a cambiarlo. En algunos casos, al volver a buscar, han encontrado otro de la misma condición -baja calidad-. Por otro lado, el no trabajar con contrato (sobre todo personas extranjeras y algunos autóctonos) provoca en las personas: una alta inestabilidad que a su vez, repercute en toda la trayectoria laboral, entrando en trabajos precarios y en sectores de actividad muy determinados, de los que luego es muy difícil salir. A su vez, el empleo precario se convierte en algunos casos, en destino «casi obligado», sobre todo cuando el nivel de formación es bajo. Sobre todo porque en el mercado de trabajo, se exige como mínimo el Graduado Escolar a la hora de ocupar un puesto de trabajo. Pero también el empleo precario se convierte en efecto y causa de sí mismo, pues en el empleo precario se constata no una cualificación «desde y por» el empleo, sino un mantenimiento al margen de la cualificación, es un empleo -el precario-, que no cualifica al individuo. 
que producimos» ${ }^{16}$. El empleo, nos proporciona relaciones sociales, seguridad emocional, prestigio/estatus, rol de trabajador/ciudadano, te hace sentirte válido, reconocido y respetado. Aportas a la Sociedad y puedes pertenecer a ella.

La participación en el mercado laboral es una de las mejores vías para conseguir una efectiva inserción social y para prevenir la exclusión social ${ }^{17}$. Si bien un empleo parece constituirse como la mejor salvaguardia frente a situaciones de exclusión social, éste, por sí solo, no es garantía de éxito. El acceso al empleo, con ser una de las medidas fundamentales y necesarias para la superación de situaciones de discriminación, no es la única que se debe aborda.

\section{Frontera crítica en la inserción laboral}

El siguiente esquema muestra el grado de dificultad en la inserción de las personas desempleadas, en función de los diferentes tramos de edad o momentos vitales. Tal y como se muestra, a apartir de los 45 años la dificultad de acceso al empleo se incrementa, considerándose en este punto la frontera crítica $^{18}$.

Las personas que tienen más de 50 años, tienen discursos más pesimistas, donde perciben que su salida de la situación de desempleo es mucho más difícil.

\section{Frontera crítica}

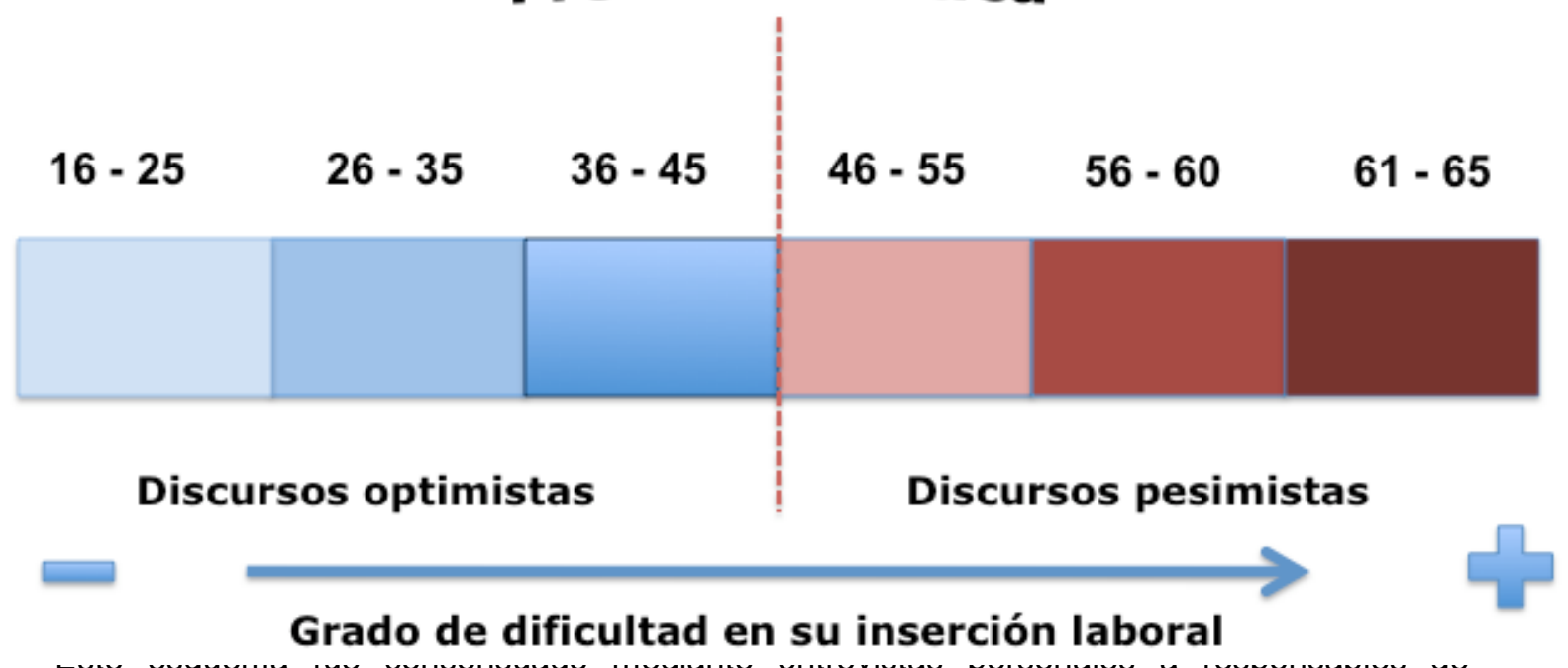

Recursos Humanos de diferentes empresas, para saber dónde colocorían -la mayoría- la frontera crítica a partir de la cuál se dificulta gravemente la inserción de las personas desempleadas. 
La literatura científica define las barreras de acceso al empleo, como aquellas limitaciones, obstáculos o impedimentos que las personas desempleadas perciben y/o poseen ante su proceso de búsqueda de empleo. Estas barreras no se suelen dar de forma aislada ni puntualmente, sino que están interrelacionadas y son de naturaleza social, personal, familiar y laboral y confluyen a lo largo de la vida de las personas desempleadas incidiendo negativamente en su desarrollo profesional.

Además, las situaciones de dificultad en el acceso al empleo, son dispares y de diferentes tipologías, marcando una casuística muy variada. Indudablemente no son lo mismo, las dificultades de una persona joven, que intenta acceder al mercado laboral por primera vez, que las de una persona con una amplia trayectoria o carrera profesional.

“- E. Qué otras barreras pueden encontrar a parte de la Formación y de la Experiencia.

- A. ¿Otras barreras?, es que dependen muchos de los perfiles profesionales.

- A. Es que aquí nos encontramos de todo. Desde no voy a la entrevista porque estoy muy lejos. Estamos hablando desde el punto de vista del demandante. Es lo que dice Lupe, porque hay aptitudes $y$ actitudes. Te cuesta mucho venir, pero no por el dinero ni por la situación ni por nada. Es que eso está muy lejos y nosotros, estamos en el Centro de Madrid. Y ya de primera, se encuentra con esta barrera, de distancia, de tres paradas de metro, porque nos ha pasado, es que estás a tres paradas de metro y dicen, bueno, no, entonces, se ve un poco, es que es muy personal, de la situación de cada uno, de las ganas, del interés. De barreras, cada uno se puede poner las que quiera. No hay algo generalizado. Lo ha dicho antes, aquí ha venido gente, con una minusvalía, y ha venido en metro, en autobús, buscando para arriba, para abajo, y ha venido a la entrevista. $Y$ otra persona, viviendo a dos paradas en metro, no viene.

- E. Es que una persona con discapacidad está acostumbrada a sortear barreras.

- A. Por eso las barreras se las pone la persona. A nivel de empresa, lo mismo. Las barreras que quiera poner la empresa, son infinitas. De edad, de distancia geográfica, a lo mejor hay gente que no le 
importa, porque se ha estado toda la vida haciendo cincuenta kilómetros para ir a trabajar. Y te dicen en la empresa, que no quieren a nadie que viva más lejos de... Entonces, es tan general lo de las barreras.

- A. Existen, existen. Y la empresa también las pone. Las pone el propio candidato cuando busca empleo, porque se pone así mismo barreras, y lo único que le hacen es dificultarle su búsqueda, y el empresario también, a la hora de seleccionar, pero porqué no vas a entrevistar a alguien de Alcorcón porque tu empresa esté Plaza de España, por favor. Si desde Alcorcón se tarda menos en llegar a Plaza de España que alguien que viva en la otra punta de Madrid. Y nosotras todo ese tipo de cosas, nos las saltamos. Es que no tendría sentido" [E.T.- 1 Técnicos/as de empleo ${ }^{19}$

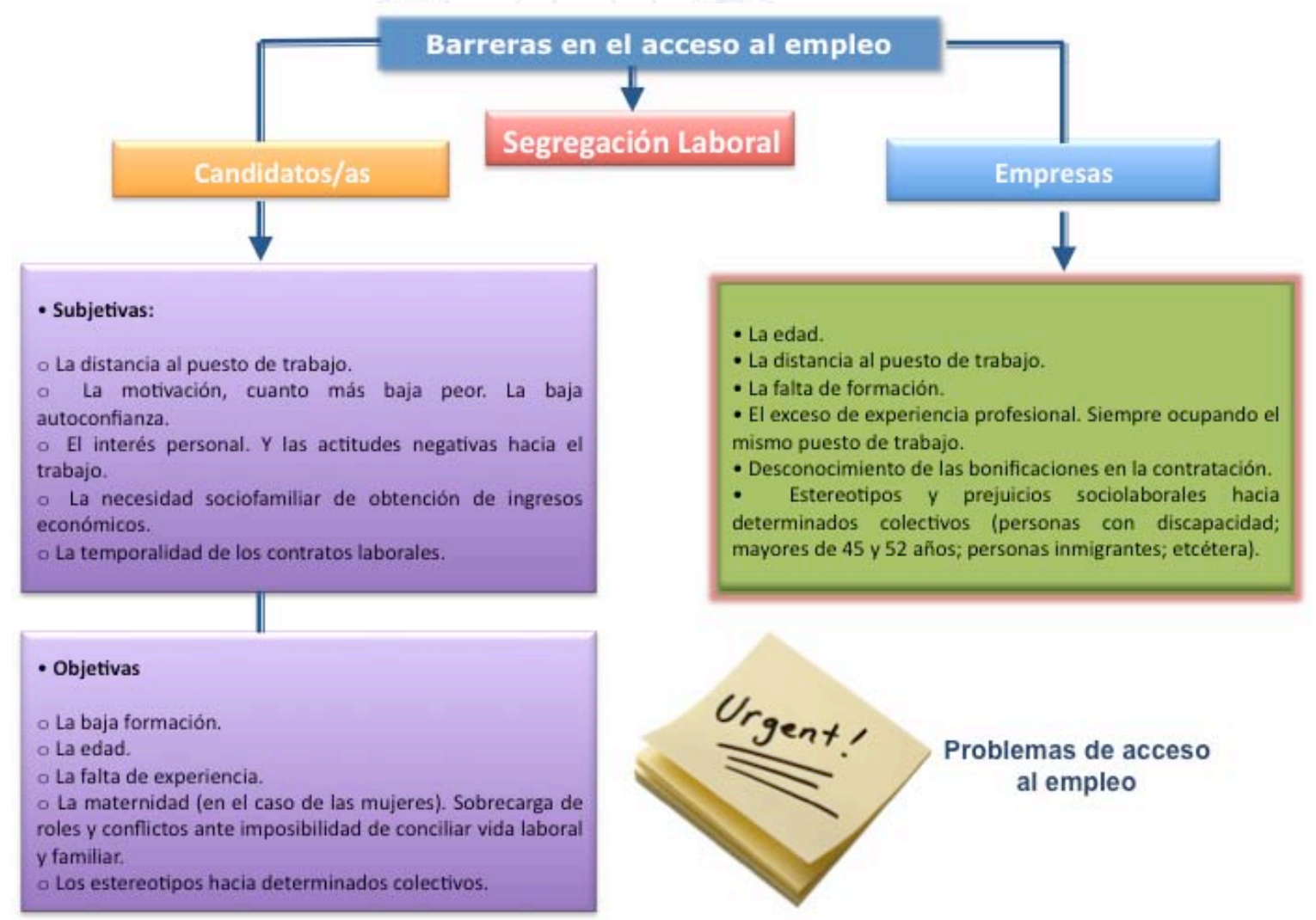

Por último, las personas desempleadas manifiestan cierta angustia sobre el hecho de lo que ocurrirá en el presente-futuro cuando las ayudas (las prestaciones por desempleo; ayudas familiares; o las medidas urgentes del

${ }^{19}$ Entrevistas realizadas por mí, para el Estudio: "aspectos sociológicos del desempleo: la expulsión/exclusión del mercado laboral", y publicado por la Secretaría de Iniciativas para el Empleo de Comisiones Obreras de Madrid en el año 2011. 
programa temporal de fomento de empleo) puedan faltar y la situación económica actual se prolongue $\mathrm{e}^{20}$.

“ - H. Que las ayudas están muy bien, hasta que se terminen. Cuando se terminen qué va a pasar. Yo hubiera preferido que nos dieran trabajo. Pero claro, si va a ser una ayuda, que va a durar un mes o dos o tres meses, un año o un año y medio, pero claro, luego llega el año y medio y se termina. A lo mejor, están bien, pero no incentivan a la gente a buscar trabajo y a ir para otros sitios, a tener más campos de visión. A lo mejor con las ayudas, pues prefieren quedarse en casa, ya que me dan cuatrocientos veinte euros, pues me quedo en casa" [GD 1.- Personas desempleadas entre 25 y 44 años]

\section{Estrategias para mejorar la empleabilidad de las personas desempleadas mayores de 45 ylo 50 años}

Soy consciente que las personas desempleadas mayores de 45 años (colectivo al que pertenezco), presentan en su mayoría una serie de sentimientos (emocionales y dudas) que les dificulta negativamente su inserción/reinserción al mercado de trabajo. Tienen sensaciones de exclusión y aislamiento que la propia situación de desempleo (que cuanto más tiempo lleven en paro, más se incrementa) crea en este colectivo. Junto con una falta de confianza propia y una cierta baja autoestima, además, en muchas ocasiones se muestran con miedo al fracaso. Todo esto determina las dificultades que encuentran/encontramos a la hora de la reincorporación al mercado laboral.

Lo primero que debemos decir, es que nos debemos reinventar profesionalmente $^{21}$. Porque ya no se tiene nada que perder. Porque la seguridad laboral actual y con la crisis tan profunda que hay, reside en nuestra habilidad para aportar valor de forma constante.

Estamos viviendo el final de la era industrial y el inicio de la era del conocimiento. Las reglas del juego del mercado de trabajo están cambiando y seguirán cambiando, cada vez más deprisa. Como muestran las estadísticas el

\footnotetext{
${ }^{20}$ El Ministro de Economía y Competitividad -Luis de Guindos- y el propio presidente del gobierno actual -Mariano Rajoy- están señalando a 2014 como el comienzo y la recuperación de la economía Española.

${ }^{21}$ Tenemos que cambiar de mentalidad. Ser capaces de introducir cambios en nuestras aptitudes y actitudes.
} 
puesto de trabajo con contrato indefinido está disminuyendo y por el contrario, se están incrementado los trabajos temporales y precarios $^{22}$.

Lo que debemos hacer es no desanimarnos ni perder la esperanza de volver a reincorporarnos al mercado de trabajo. Encontrarse desempleado o desempleada es una situación estresantes y complicada. Pero si deseamos realizar un itinerario hacia el cambio, no debemos dejarnos llevar por la queja, ni por el victimismo y menos por la culpa. Esto nos llevaría a consumir negativamente nuestra energía vital, la que necesitamos para buscar nuevas soluciones y alternativas.

Es importante invertir tiempo en conocernos lo más profundamente (sobre todo desde el punto de vista personal y profesional) que podamos o que seamos capaces. Aprendiendo cómo volver a motivarnos, a elevar nuestra autoestima y generar confianza en nosotros mismos. Es decir, a descubrir nuestras fortalezas internas y las profesionales (buscar salidas profesionales), lo que nos llevará a afrontar la adversidad -de la vida y del mercado laboral- de una forma más responsable, optimista, eficaz y eficientemente.

Para las personas que llevan poco tiempo desempleadas, buscar empleo cuanto antes. $Y$ para todos y todas, abrir lo más posible el abanico de posibilidades $^{23}$, ya que puede que no encontremos un empleo como el anterior que teníamos/desarrollábamos. Lo más importante es encontrar uno y poder mantenerlo, hasta que seamos capaces de encontrar nuestro verdadero propósito laboral -el que más sentido tenga para nosotros/as o el vocacional-. Hacer algo que nos apasione, que potencie nuestro talento.

Debemos ser capaces de desarrollar nuestra marca personal (el marketing personal), nuestros puntos fuertes (la edad es uno de ellos). Las personas más jóvenes pueden mostrar más vitalidad e incluso están más preparados para absorver y utilizar las nuevas tecnologías, que puede que a las personas de más edad, les pueda costar. Debemos tener claro que es muy importante la forma en la que nos comunicamos y les decimos a los demás, cómo somos y de lo que somos capaces de hacer. Recordar que las empresas buscan personas competentes, capaces de trabajar en equipo, que sean capaces de

\footnotetext{
${ }^{22}$ El empleo de toda la vida se está convirtiendo en algo del pasado y va dejando paso a una movilidad laboral permanente.
} 
relacionarse con el resto de personas, capaces de adaptarse a las diversas situaciones por las que pase la empresa (polivalencia, multifuncionalidad....), madurez emocional (producto de las experiencias vitales vividas por las personas) y luego, formación ${ }^{24}$-que siempre es necesaria- o la capacidad para poder recibirla dentro y fuera de la empresa. La formación continua y la información es cada vez más importante. Todo esto junto, conformará el reflejo de tu persona ${ }^{25}$ (la personal y la profesional). Por último, no te olvides de tus contactos profesionales y personales.

Cuadro sobre los puntos débiles y fuertas que podamos tener

\begin{tabular}{|c|c|c|c|}
\hline & Puntos débiles & Puntos fuertes & $\begin{array}{c}\text { Estrategias a } \\
\text { emplear }\end{array}$ \\
\hline $\begin{array}{l}\text { Inserción/reinserción } \\
\text { laboral }\end{array}$ & 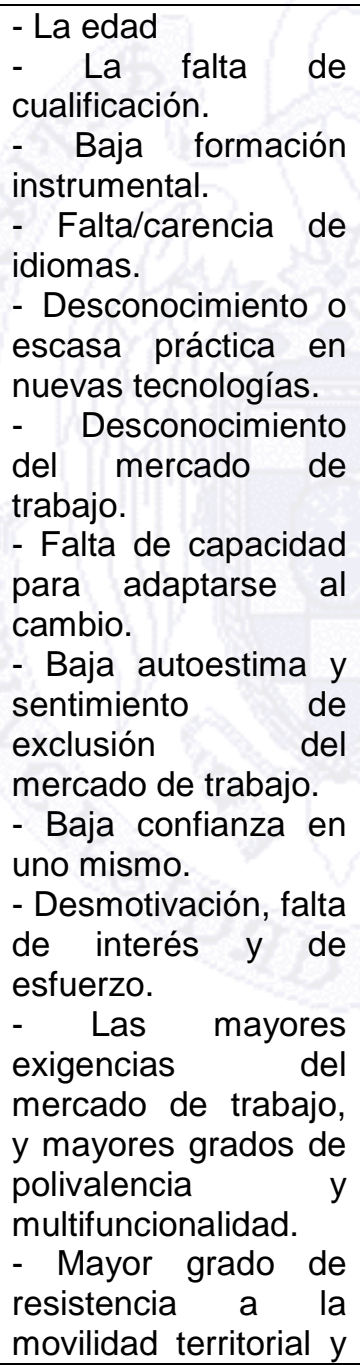 & $\begin{array}{l}\text { - Alta necesidad de } \\
\text { inserción laboral. } \\
\text { - La experiencia } \\
\text { adquirida a través de } \\
\text { los años (social y } \\
\text { laboral). } \\
\text { - Fuente de } \\
\text { conocimientos. } \\
\text { - Capacidad de } \\
\text { relaciones } \\
\text { interpersonales (si las } \\
\text { tuviere). } \\
\text { - Capacidad de de } \\
\text { resolución } \\
\text { conflictos/problemas. } \\
\text { - Capacidad de } \\
\text { autoreflexión. } \\
\text { - Madurez personal y } \\
\text { profesional. } \\
\text { - Alta responsabilidad } \\
\text { y compromiso para el } \\
\text { trabajo. } \\
\text { - Mayor rendimiento } \\
\text { en el puesto trabajo. } \\
\text { - Menor distración. } \\
\text { - Capacidad de de } \\
\text { recuperación de de } \\
\text { oficios. }\end{array}$ & 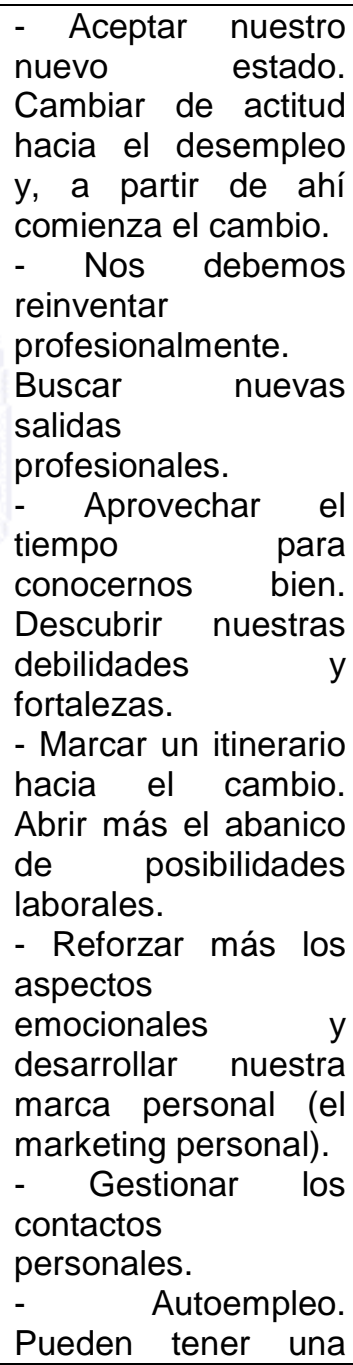 \\
\hline
\end{tabular}

${ }^{23}$ Es importante conocer el funcionamiento del mercado de trabajo, ésto puede sernos de utilidad si queremos conseguir un empleo.

${ }^{24}$ El colectivo de personas desempleadas mayores de 45 años, puede presentar un déficit en su formación. La falta de la misma, se puede explicar -en muchos casos- por la juventud con la que se iniciaron en su vida laboral.

${ }^{25}$ Tú eres el único o la única que sabes cuál es tu propio valor. Lo que te digan los demás, es complementario pero no definitorio de su personalidad. 


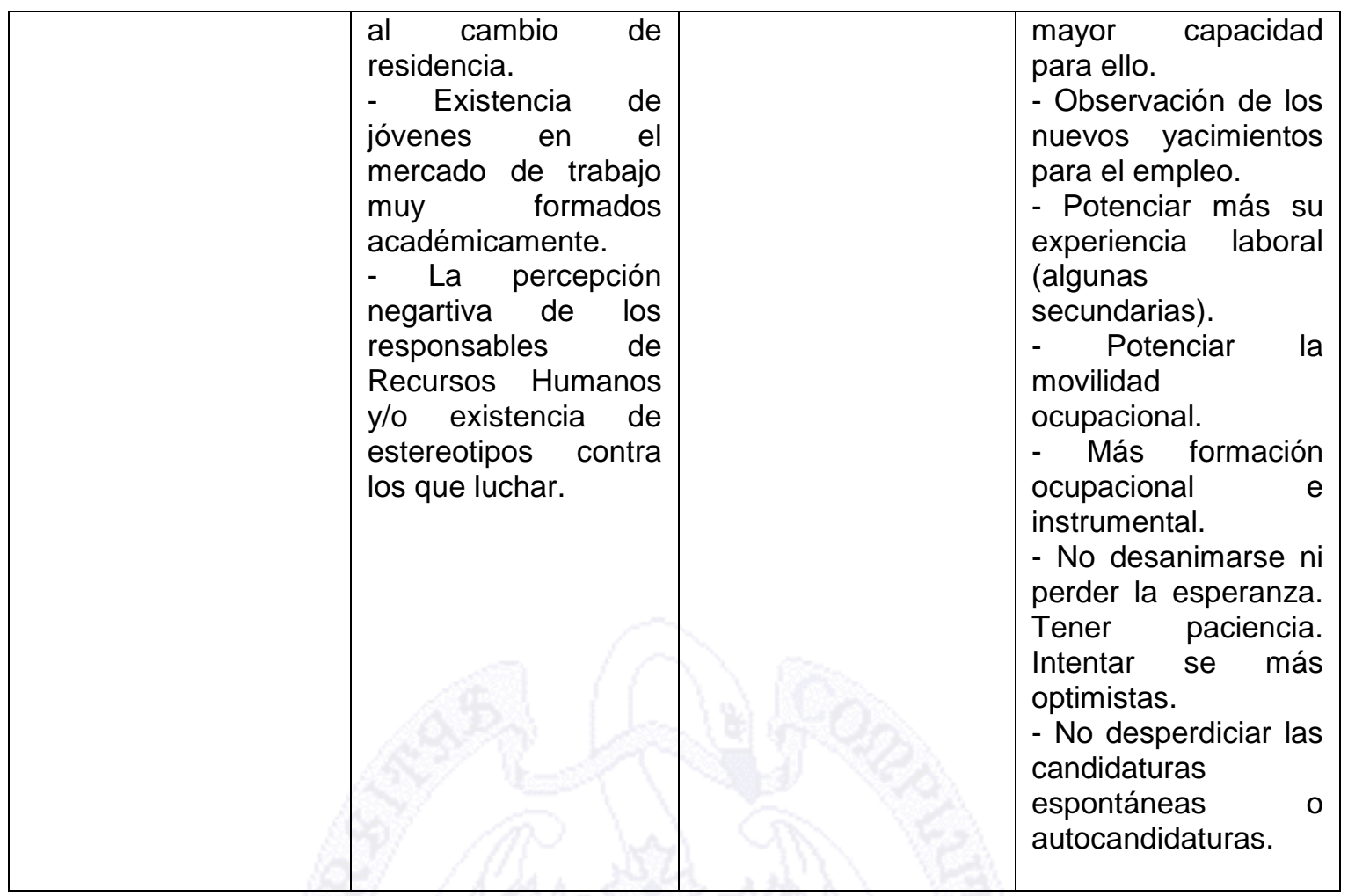

Fuente: Elaboración propia.

\section{Conclusiones}

Tengo 50 años o más y ¿qué?, tenemos la edad que tenemos y no podemos ocultarla -sí disimularla-, pero debemos ser capaces de dar la vuelta a nuestra situación, para centrarnos más en aquello que podemos ofrecer a los demás, tratándo de minimizar el factor negativo que pudiera ser la edad. Es verdad que social y laboralmente se demandan en el mercado de trabajo, personas más jovenes. Pero debemos extraer lecturas positivas sobre nuestra edad y de nuestro potencial. Debemos ser capaces de eliminar los estereotipos -hacia la edad- que pudieran tener los responsables de Recursos Humanos de las empresas. Soy consciente que tener más de 45 años y encontrarse de repente en desempleo y/o en paro es un drama para la mayoría de las personas afectadas, pero si además, tienes 50 o más, se agrava nuestra situación personal, social y familiar con más estrés. Debemos asumir de forma cada vez más habitual los riesgos ${ }^{26}$-más o menos razonables- y saber encajar los fracasos de forma postivia -entendiendo esto como un aprendizaje, como como algo traumático-.

\footnotetext{
${ }^{26}$ Esto tiene que ver con la tolerancia y el riesgo a la incertidumbre. Porque si algo debemos saber sobre el futuro, es que será distinto de lo que conocemos actualmente.
} 
Las personas mayores de 45 años tienen en común una misma circunstancia: la edad. Edad que por otro lado, se vuelve un hándicap cuando intentas retornar/volver al mercado de trabajo. Agravándose su situación cuanto más tiempo se encuentre la persona desempleada. Porque baja su autoestima, y pierde motivación para regresar al mercado laboral. Por otro lado, la competencia en él, es mayor (tanto cuantitativamente, pues hay muchísimas personas desmpleadas, como cualitativamente, porque están cada vez más preparados desde el punto de vista de la formación académica, complementaria, con idiomas.....). También es común que la búsqueda de empleo se haga sin orden ni concierto. Debemos recordar, que en los tiempos que corremos, lo frecuente es que la búsqueda sea un proceso que se prolongue más de lo deseable en el tiempo y sin cierta planificación es fácil que pasen los días, sin que hayamos hecho nada que nos acerque más a conseguir un trabajo o que nos encontremos con no saber qué hacer. Por tanto, encontrar trabajo requiere de cierto orden y planificación. ¡Suerte!. 